\title{
A REPRESENTATIVIDADE DO SERTÃO MINEIRO PELAS VEREDAS DA LITERATURA ROSEANA
}

\section{THE REPRESENTATIVITY OF THE SERTÃO MINEIRO THROUGH THE PATHWAYS OF ROSEAN LITERATURE}

\author{
Maria Luiza Rodrigues*
}

\begin{abstract}
RESUMO
O objetivo do artigo em questão é apresentar, por meio do clássico literário 'Grande Sertão: Veredas' de João Guimarães Rosa, uma análise das diversas faces do sertão de Minas Gerais, local quase sempre colocado à margem na historiografia. Neste sentido, parte-se de uma observação acerca do conceito desertão nas produções intelectuais brasileiras ao longo dos séculos, tendo seu foco na escrita de Rosa, visto que o autor narra os atores e processos do espaço com uma singularidade inédita. Assim, este trabalho busca demonstrar como a narrativa roseana representa a região, contribuindo diretamente com a história eas vivências de Minas Gerais.
\end{abstract}

Palavras-chave: Guimarães Rosa. Grande Sertão: Veredas. Minas Gerais.

\begin{abstract}
The objective of the article in question is to present, through the literary classic 'Grande Sertão: Veredas' by João Guimarães Rosa, an analysis of the different faces of the Minas Gerais hinterland, a place almost always placed on the margins of historiography. In this sense, it starts with an observation about the concept of the sertão in Brazilian intellectual productions over the centuries, focusing on Rosa's writing, as the author narrates the actors and processes of space with an unprecedented singularity. Thus, this work seeks to demonstrate how the Rosean narrative represents the region, contributing directly to the history and experiences of Minas Gerais.
\end{abstract}

Keywords: Guimarães Rosa. The Devil to Pay in the Backlands. Minas Gerais.

'Por ser de lá do sertão, lá do cerrado

Lá do interior do mato

Da caatinga do roçado

Eu quase que não consigo

Ficar na cidade sem viver contrariado

$[\ldots]$

Sou como rês desgarrada

Nessa multidão boiada caminhando a esmo",

Artigo submetido em 21 de julho de 2021 e aprovado em 10 de setembro de 2021 .

* Graduanda em Direito pela Pontifícia Universidade Católica de Minas Gerais. E-mail: malusimpliciord@gmail.com. 
Lamento Sertanejo - Dominguinhos e Gilberto Gil

"Sertão: é dentro da gente". Guimarães Rosa, Grande Sertão Veredas.

\section{INTRODUÇÃO}

João Guimarães Rosa, mineiro de Cordisburgo, presenteou a literatura brasileiracom uma de suas obras mais revolucionárias e intrigantes. O romance que não possui divisão em capítulos e se desdobra por mais de 600 páginas, apresentou-se como um divisor de águas no meio intelectual do país, por narrar de forma extremamente particular e inovadora a dialética do bem e do mal e a travessia em que se constitui a existência humana, além de suscitar as mais diversas reflexões, por meio do cenário antes de invisibilidade do sertão mineiro.

O literato, que também se dedicou à medicina e à diplomacia, destacou-se principalmente pelo uso das mais diversas expressões regionais em suas obras,que mescladas a neologismos, palavras estrangeiras e construções de frases desafiadoras ao leitor, deram, a partir da obra, uma dimensão completamente nova do sertanejo e do seu mundo. Desse modo, embora não possa serconsiderado vanguardista, pelo alto grau de complexidade de sua obra Rosa pode ser classificado como um inventor, como apresentou Ezra Pound, em sua classificação de escritores, que seriam "homens que descobriram um novo processo ou cuja obra nos dá o primeiro exemplo conhecido de um processo." (POUND, 1970, p.42).

Pode-se dizer que Rosa construiu em seus registros literários um "'inventário" das mais diversas faces de Minas Gerais, especialmente em Grande Sertão: Veredas, onde descreveu detalhadamente diversos elementos marcantes do espaço, como a vegetação e o relevo presentes (MEYER, 2006), além do modo de vida do sertanejo manifestado nos personagens da obra. Desse modo, constata-se queo autor contribuiu grandemente para a difusão da verdadeira realidade acerca das vivências dos moradores do sertão mineiro. Para tecer a trama de Grande Sertão, Rosa realizou múltiplas excursões pela região na década de 1940, a partir das quais anotou observações sobre os costumes, a fauna e a flora locais,registradas nos famosos cadernos que o autor levava consigo durante a histórica

Ao dar início a uma observação acerca da identidade mineira na escrita de Guimarães Rosa, seus relatos sobre o Estado em que nasceu demonstram seuenorme apreço e estima por suas origens e valores. Em agosto de 1957, publicana revista O Cruzeiro, um texto em que exalta e destaca as belezas, nuances eas principais características de Minas Gerais:

[..] Sobre o que, em seu território, ela ajunta de tudo, os extremos, delimita, aproxima, propõe transição, une ou mistura:no clima, na flora, na fauna, nos costumes, na geografia, lá se dão encontro, concordemente, as diferentes partes do Brasil. Seu orbe é uma pequena síntese, uma encruzilhada; pois Minas Gerais é muitas. São, pelo menos, várias Minas. [..]. Minas semmar, Minas em mim: Minas comigo. Minas. (ROSA, 1957).

Por meio da leitura da multiplicidade das 'Minas' de Rosa, nota-se sua admiraçãopelo Estado e pelas suas tradições interioranas. A partir do regionalismo transcrito para as páginas de Grande Sertão: Veredas e a valorização da culturapopular ao apresentar o sertão para o mundo, a complexidade da obra é uma motivação para refletir-se acerca de questões como o conceito de sertão, a relação dos habitantes dos sertanejos mineiros com o espaço e a universalização da vida e dos dilemas destes indivíduos.

\section{O QUE É O SERTÃO?}

As diferentes ideias repercutidas ao longo das décadas sobre o Sertão foram compostas 
não somente de aspectos geográficos ${ }^{1}$, mas também de representações equivocadas acerca de sua população e suas vivências, como as de um local que remete à ausência de civilização. $\mathrm{O}$ tema é discutido e analisado em áreas como a geografia, a história e a sociologia, e, portanto, para uma compreensão de suas verdadeiras vivências, é necessário resgatar sua história e seu processo de formação.

A Carta de Pero Vaz de Caminha, de 1500, é identificada como o primeiro documento a registrar a palavra sertão no Brasil. Em determinada passagem, tem-se: "Pelo sertão nos pareceu, vista do mar, muito grande, porque, a estenderolhos, não podíamos ver senão terra com arvoredos, que nos parecia muito longa." (MARQUES, A.; BERUTTI, F.; FARIA, R., 2001)

A partir da análise de documentos do período da colonização portuguesa no Brasil, pode-se constatar a percepção que difundiu-se entre os viajantes do período: um contraste profundo entre o litoral e o sertão. Por meio da oposição entre a vista do mar e a terra distante como é demonstrado na carta, o sertão era descrito como um local vasto o suficiente para não chegar ao alcance dos olhos.

De acordo com Boris Fausto (2019), durante as tentativas iniciais de exploração, o Brasil aparecia como uma terra de possibilidades geográficas desconhecidas, epor vários anos, era vista apenas como uma grande ilha. Assim, a grande maioriadas viagens que percorreram o território brasileiro do século XVI ao século XVII,basearam-se na utilização do termo para classificar algo distante do litoral, dadoque a terra como um todo era uma incógnita. Os primeiros cronistas da época colonial, portanto, enxergavam o sertão por um único prisma: o de ser afastado dos principais núcleos populacionais, algo consequentemente tornava a sua visitação uma árdua tarefa e um ato até mesmo classificado como perigoso ${ }^{2}$.

Em relação ao sertão mineiro, destaca-se que a formação do Estado ocorreu a partir do processo de descobrimento do ouro e dos conflitos acarretados por esse fator. Após a Guerra dos Emboabas (1708-1709), a Capitania do Rio de Janeirofoi dividida entre a Capitania de São Paulo e a de Minas do Ouro, que após a Revolta de Filipe dos Santo sofreu outra divisão, que em 1720 deu origem à Capitania de Minas Gerais. A Capitania era dividida teoricamente em 4 partes: Comarca do Rio das Velhas, Comarca do Rio das Mortes, Comarca de Vila Ricae Comarca do Serro Frio, apesar do fato de que os limites entre elas e até mesmoentre as próprias capitanias não estavam bem definidos.

Nesses locais, as concessões de sesmarias geraram uma expansão na ocupação do território, marcada por atividades como a agricultura, a mineração e a pecuária. No oeste, em conjunto com práticas como a pesca e a caça, iniciou-se o desenvolvimento de uma sociedade sertaneja que "se caracterizou por umaorganização social e política próprias, distante dos centros de poder, [visto que] as distâncias e o próprio meio ambiente dificultavam as ações das autoridades coloniais" (RIBEIRO, 2005, p. 246).

A partir da delimitação compreendida como o sertão mineiro, foram elaboradas diversas representações da região. Com destaque sempre à sua grandiosidade,construiu-se o imaginário de um local com enormes extensões de terras e de umvazio, por meio do olhar do estrangeiro que insistia em representar um aspecto de predominância da barbárie e de indivíduos nãocivilizados. Em síntese, é notório que os registros históricos desse período foram influenciados pelas marcas de um processo colonizador, em que o diferente era classificado como oinculto e o desconhecido, e o observador sempre relacionado ao culto e ao conhecido, civilizado.

Percorrendo a história, ao fazer uma reflexão sobre o período após a Revoluçãode 1930

\footnotetext{
${ }^{1}$ Durante o período da colonização portuguesa, existia uma ' geografia imaginária'” acerca do sertão, que era visto como um espaço constituído de um imenso vazio. A colonização representava a dominação sobre o território e seus habitantes, por meio da formação de vilas, criação de gado e exploração de metais preciosos.

${ }^{2}$ Pero de Magalhães Gândavo, historiador e cronista português, demonstra no Tratado da Terra do Brasil o medo em relação ao local, relatando que "ninguém pode pelo Sertão dentro caminhar seguro nem passar por terra onde não ache povoações de índios armados contra as nações humanas.'”
} 
até o fim do Estado Novo, nota-se que houveram mudanças profundasno âmbito da política institucional no país, em que emergiram, em conjunto coma modernização industrial, novos parâmetros nas relações sociais.Anteriormente, já no século XX, Euclides da Cunha publicava a obra Os Sertões,em que apresentava o sertanejo como cerne da sociedade. Porém, a partir dos anos 30, intelectuais como Sérgio Buarque de Holanda, Celso Furtado, Gilberto Freyre, Antônio Cândido e Caio Prado Jr investigaram processos e aspectos daconfiguração da vida social brasileira e seus respectivos retratos a partir de um olhar ensaístico ${ }^{3}$. Com o foco na análise da formação nacional, os intelectuais se posicionaram em uma busca para entender a realidade brasileira, por um processo que pudesse colaborar no reconhecimento de seu verdadeiro retrato apartir das experiências históricas.

No contexto das obras produzidas entre 1940 e 1950, nasce Grande Sertão: Veredas, que conquanto seja uma obra de ficção, pode ser classificada entre uma das que colaboraram profundamente para uma análise coerente do retratodo Brasil ${ }^{4}$, e consequentemente, do sertão. Rosa apresenta diversos elementosno romance que corroboraram para construir o conceito de formação do país, visto que por meio de Riobaldo tem-se uma análise da história social do sertão brasileiro, e o narrador leva a obra a uma posição de destaque:

\begin{abstract}
É o narrador que encena as estruturas sociais, especialmente ostipos de discursos que representam as forças históricas atuantes [...]. Essas forças históricas ganham vida através da elaboração existencial pelo narrador, que se sente profundamente concernido por essas questões [...]. É a figura do narrador que proporciona o salto qualitativo de Grande Sertão: Veredas comoromance de formação do indivíduo para romance de formação do país. (BOLLE, 2004, p.368).
\end{abstract}

Nas primeiras páginas da obra compreende-se que o Sertão mineiro na descrição de Rosa não se limita apenas a um espaço geográfico, tendo em vistaas incontáveis alusões ao sertão que se apresentam de forma transcendental, oque a diferencia das produções anteriores focadas no sertão físico em si. Aqui, "O sertão está em toda a parte” (ROSA, 2018, p. 13), '’O sertão é onde manda quem é forte, com as astúcias" (ROSA, 2018, p. 21), "O sertão é do tamanho do mundo" (ROSA, 2018, p. 59). Assim, Guimarães Rosa redimensiona este conceito, fazendo-o ultrapassar as ideias delimitadas anteriormente, uma vez que o termo assume diversos significados por meio das metáforas. O sertão ultrapassa qualquer tentativa de delimitação, e não se encaixa na ideia da literatura dos viajantes: o sertão é o viver, é o ser humano e tudo que o perpassa.

\title{
3 O SERTANEJO E SEU ESPAÇO
}

O autor, ao partir da descrição do sertão no Norte do Estado de Minas Gerais, faz uma intersecção entre o real e o fantástico e apresenta ao leitor uma outra dimensão da região e do modo de vida de seus moradores, como os ribeirinhos, sertanejos e os povos tradicionais, compartilhando a pluralidade de vivências e existências. O personagem-narrador Riobaldo conta o Sertão e sua história de vida de modo nostálgico, o que não acarreta em uma ordem cronológica dos fatos ocorridos, mas sim, em um registro histórico que se desdobra por meio desuas lembranças.

\footnotetext{
${ }^{3}$ Refiro-me a Raízes do Brasil (Sérgio Buarque de Holanda, 1936), Formação econômica do Brasil (Celso Furtado, 1959), Casa grande e senzala (Gilberto Freyre, 1933), Formação da literatura brasileira (Antonio Candido, 1959), e Formação do Brasil contemporâneo (Caio Prado Jr., 1942).

${ }^{4} \mathrm{O}$ termo 'retrato do Brasil' é utilizado em referência à obra 'Retrato do Brasil: Ensaio Sobre a Tristeza Brasileira', de Paulo Prado. Publicado em 1928, o livro foi um catalisador para outros estudos voltados à compreensão do Brasil.
} 
Contar é muito, muito dificultoso. Não pelos anos que se já passaram. Mas pela astúcia que têm certas coisas passadas - de fazer balancê, de se remexerem dos lugares. $\mathrm{O}$ que eu falei foi exato? Foi. Mas teria sido? Agora acho que nem não. São tantas horas de pessoas, tantas coisas em tantos tempos, tudo miúdo recruzado (ROSA, 2018, p. 136).

Esse fato, em conjunto com os registros feitos em suas viagens ao local, permitiua Rosa uma fiel representação da sociedade sertaneja de Minas Gerais, pois uma imensa rede de falas tradicionais do sertão compõe o registro de Riobaldo.Assim, o autor se utiliza dos mais diversos elementos da cultura oral presente naregião, e dessa maneira, ao invés de descrever o povo, gera umaautorrepresentação através de suas falas, contando a história a partir de vivências do cotidiano.

Em meio às digressões de Riobaldo perante a sua existência, o Rio SãoFrancisco é um dos meios físicos que se apresentam além de um elemento geográfico e torna-se a representação de uma realidade mágica ${ }^{5} \mathrm{O}$ Velho Chico, como é popularmente conhecido, passa por cinco Estados brasileiros e nasce no Parque Nacional da Serra da Canastra no município de São Roque deMinas, banhando cidades como Januária, Matias Cardoso, Pirapora, São Romãoe Três Marias. O Norte de Minas ganha amplidão máxima ao ter o Rio como umdos aspectos fundamentais para o desenvolvimento da história: o São Francisco,na obra, divide o mundo sertanejo de Riobaldo no lado direito (em que a vida corre normalmente, sendo a margem do justiceiro Joca Ramiro e de sua amizadee amor por Diadorim), e no lado esquerdo (o lado da vingança, do rival Hermógenes e de acontecimentos obscuros). ${ }^{6}$

Tendo como objeto de análise a população sertaneja mineira, ainda se faz presente outro elemento de destaque na obra: os jagunços. Ao estabelecer-se uma análise do conceito, este pode ser definido como:

empregado a soldo dos latifundiários e fazendeiros, arregimentado entre aqueles que não tinham terra nem trabalho ou entre os homens livres da plebe rural, como os agregados oumoradores, colocavam-se a serviço dos coronéis e estabeleciamcom eles uma relação de dependência, oferecendo seu braço armado em troca de proteção. Fruto da condição semi-servil deagregados, camaradas e rendeiros e do monopólio da terra, os apaniguados dos grandes proprietários exerciam função policialao mesmo tempo que constituíam uma força utilizada para o exercício do poder. (VASCONCELOS, 2002, pag. 327)

Ao narrar a guerra jagunça, Rosa demonstra o exercício privado do poder e os reflexos da violência em uma sociedade. Os jagunços de Grande Sertão são homens livres que escolhem a jagunçagem pelos mais diversos motivos, e o autor diversas vezes descreve a organização dos bandos, assim como seu cotidiano e seus costumes. O autor retrata os reflexos das crises econômicas, sociais e políticas que se apresentaram durante a República Velha (1889-1930), agravadas por movimentos de massas sertanejas assoladas por diversas mazelas, como a seca e a fome, gerando a disseminação de jagunços e cangaceiros (no caso do Nordeste brasileiro), e sistemas como o coronelismo fazendo oposição à lei do Estado.

(...) Por que o Governo não cuida?! Ah, eu sei que não é possível. Não me assente o senhor por beócio. Uma coisa é pôrideias arranjadas, outra é lidar com país de pessoas, de carne esangue, de mil-e-tantas misérias. Tanta gente - dá susto se saber - e nenhum se sossega: todos nascendo, crescendo e secasando, querendo colocação de emprego, comida, saúde, riqueza, ser importante, querendo chuva e negócios bons...(ROSA,

\footnotetext{
${ }^{5}$ Rosa também utiliza o rio como metáfora para explicar o modelo de narrativa. Riobaldo diz ' penso como um rio tanto anda: que as árvores da beirada mal nem vejo', (ROSA, 2018, p. 248)

${ }^{6}$ Riobaldo cita em determinada passagem '’O São Francisco partiu minha vida em duas partes'. (ROSA, 2018, p. 224).
} 
2018, p. 18)

Riobaldo, ao dizer que "'viver é muito perigoso", revela um retrato dos indivíduos sertanejos que são marcados pela coragem como um elemento indissociável doser, que vivem em um ambiente coordenado por códigos próprios de justiça e que tem um comportamento diretamente influenciado muitas vezes pelo lado mais cruel da vida. Em uma análise dos personagens a partir desse aspecto, nota-se o desejo de Rosa de demonstrar que o sertão, ao ser retratado entre o real e o imaginário, evidencia uma brutalidade que se reflete no indivíduo ao buscar sua própria sobrevivência, constituindo assim uma representação do povo como forte e destemido.

\section{O SERTÃO COMO O MUNDO}

Uma das principais características presentes na obra de Rosa é proporcionar à realidade sertaneja uma dimensão global. É um livro marcado pela ambiguidade,pelos opostos e pelos impasses que marcam existência dos homens: as escolhas presentes na história não são dilemas apenas do sertanejo, mas sim, dos seres humanos de qualquer lugar do mundo. Os questionamentos sobre a existência do Diabo e de Deus, a vida e a morte, o que é e o que não é, a guerrae a paz, são demonstrações da dimensão transcendental do sertão roseano.

Riobaldo, durante sua trajetória pelas veredas do sertão, medita questionamentos universais e inerentes a qualquer indivíduo. O personagem diversas vezes promove reflexões sobre aspectos metafísicos como a religião e a existência do Diabo, levando o leitor a colocar-se em seu lugar e promovendouma contemplação conjunta.

Por isso é que se carece principalmente de religião: para se desendoidecer, desdoidar. Reza é que sara da loucura. No geral. Isso é que é a salvação-da-alma... Muita religião, seu moço! Eucá, não perco ocasião de religião. Aproveito de todas. Bebo água de todo rio... Uma só para mim é pouca, talvez não me chegue".(ROSA, 2018, p. 19)

Outro aspecto que merece destaque é a relação entre Diadorim e Riobaldo. O personagem se apaixona profundamente ao decorrer da trama por Diadorim, quese veste e se apresenta como um homem (Reinaldo). Assim, o autor traz ao debate o tema da paixão homossexual - que seria inaceitável no meio jagunço -e demonstra todos os sentimentos repressivos de Riobaldo: durante a vida de Diadorim, os dois não se relacionam pela interjeição da questão moral, e após omomento da morte do personagem, Riobaldo descobre que seu amor era uma mulher.

Deixei meu corpo querer Diadorim; minha alma? Eu tinha recordação do cheiro dele. Mesmo no escuro, assim, eu tinha aquele fino das feições, que eu não podia divulgar, mas lembrava, referido na fantasia da ideia. Diadorim - mesmo o bravo guerreiro ele era para tanto carinho: minha repentina vontade era beijar aquele perfume no pescoço: a lá, aonde se acabava e remansava a dureza do queijo, do rosto... Beleza oque é? (ROSA, 2018, p. 412)

O personagem organiza a imagem de Diadorim com extrema ambiguidade: assim como convivia com seu corpo jagunço, uma atividade vista como masculina, percebia o cuidado que possuía e até mesmo a delicadeza de sua pele e de suas atitudes em determinadas situações; os sentimentos de Riobaldopor Diadorim, com a dualidade trabalhada por Rosa, constituem uma das mais famosas e belas histórias de amor da literatura brasileira.

Virginia Woolf cita em uma de suas principais obras, que "Em cada ser humanoocorre uma vacilação entre um sexo e outro; e às vezes só as roupas conservama aparência masculina ou feminina, quando, interiormente, o sexo está em completa oposição com o que se encontra 
à vista" (WOLF, 1982). Por isso, o amor entre os personagens dá-se como impossível, visto que como Diadorim se vestia de modo masculino - para que pudesse se dedicar a explorar o Sertão -, homem era na visão dos outros jagunços. Quando Rosa exprime por meio de Riobaldo que "'as pessoas não estão sempre iguais, ainda não foram terminadas - mas que elas vão sempre mudando", pode-se analisar que Diadorim representa um conceito fluido na concepção de gênero, levando ao sertão um tema consideradocomo tabu universal à época.

As dúvidas e os conflitos pessoais de Riobaldo tomam uma amplidão que conseguem representar qualquer indivíduo: o sertão de Minas torna-se o mundo.A obra finda-se com a palavra 'travessia', representando a vida humana com todos os seus acontecimentos, e se relaciona com o próprio título da obra. Se osertão contempla o ser e o mundo, as veredas são os caminhos buscados pelo homem para compreender sua própria existência, compreensão esta que se fazpor meio da travessia. Assim como a engrenagem da vida pode ser representadapelo devir Heraclitiano ${ }^{7}$, Rosa utiliza o Rio São Francisco como o palco para o indivíduo que atravessa pela vida em um fluxo constante.

\section{CONSIDERAÇÕES FINAIS}

Grande Sertão: Veredas tornou-se uma obra de destaque no meio intelectual e uma narrativa fundamental da literatura do país. Ao utilizar-se de uma linguagempeculiar, de seus estudos e reflexões sobre Minas Gerais, Rosa revelou Minas ao mundo por meio de um sertão jamais encontrado anteriormente em outras narrativas.

O projeto literário do autor se constituiu em apresentar uma visão do local que não fosse definida por olhares estrangeiros ou apenas panorâmicos. Desse modo, a narrativa Roseana não se constituiu apenas como um simples relato dosertanejo, pois consegue integrar as histórias de vida dos indivíduos a uma nova representação do seu local de vida, com todas as suas peculiaridades e experiências singulares. Gerou-se então uma historiografia tradicional: pelas veredas do cotidiano do sertão se descobre um novo modo de escrever e representar suas tradições, questionando o que antesera imposto pelo modo universalista e as influências de um pensamento europeu. As veredas são caminhos que demonstram a transcendência dos limites de um território, pois a travessia de Riobaldo é o viver de qualquer indivíduo.

$\mathrm{O}$ ilustre representante do Estado negou a literatura influenciada pelos movimentos tradicionais e preferiu escrever uma obra marcada pelo regionalismo, abordando questões universais através do povo sertanejo mineiroe valorizando indiscutivelmente, a cultura popular. Na literatura produzida ao longo dos trezentos anos de Minas Gerais, Guimarães Rosa consegue integrar nosso passado e presente por meio de uma singularidade ímpar em sua escritae seu modo de interpretar o local onde nasceu.

As várias Minas ao longo da história estiveram em um movimento constante pormeio de suas transformações culturais, econômicas, políticas e sociais. Ao retratar o lado antes desconhecido do Estado, Rosa deixa um pedaço de Minasem cada leitor por meio das reflexões e filosofias presentes na obra. Se "o sertãoé dentro da gente', Grande Sertão: Veredas demonstra que se pode ser-tão emvários aspectos da vida; e nestes trezentos anos, Rosa continua a ser-tão mineiro, inspirando as futuras produções literárias e novas perspectivas acerca da representação de Minas Gerais.

\footnotetext{
${ }^{7}$ Heráclito de Éfeso (540 - 570 a.C), proporcionou grandes avanços para a filosofia ao elucidar o conceito de 'devir': para o filósofo, o mundo está sempre em um perpétuo fluxo, e apenas a mudança pode ser classificada como algo permanente
} 


\section{REFERÊNCIAS}

BOLLE, Willi. grandesertão.br: o romance de formação do Brasil. São Paulo: Editora 34/Livraria Duas Cidades, 2004.

Carta de Pero Vaz de Caminha. In: MARQUES, A.; BERUTTI, F.; FARIA, R. História moderna através de textos. São Paulo: Contexto, 2001.

CÂNDIDO, Antônio. O homem dos avessos. In: CÂNDIDO, Antônio. Tese e antítese. $3^{\mathrm{a}}$ ed. SãoPaulo: Companhia Editora Nacional, 1978.

DANTAS, S. M. Nos primórdios era natureza, mas o sertão foi civilizado. A relação história e natureza na ocupação do Triângulo Mineiro. Ponta de Lança: Revista Eletrônica de História, Memória \& Cultura, v. 13, n. 24, p. 77-90, 31 ago.2019

FAUSTO, Boris. História do Brasil. 14. ed. atual. e ampl., 3. reimpr. - São Paulo: Editora da Universidade de São Paulo, 2019. (Didática, 1).

MEYER, M. As Anotações de Viagem de Guimarães Rosa pelo Sertão de Minas Gerais.

Revista Graphos, v. 1, n. 1, 1 jan. 2006.

O SÉCULO 18 nas Minas Gerais. [S. l.], 11 jul. 2019. Disponível em:

http://www.cultura.mg.gov.br/component/gmg/story/5696-o-seculo-18-nas- minas-gerais. Acesso em: 23 set. 2020.

RIBEIRO, Ricardo F. Florestas anãs do sertão: o cerrado na história de Minas Gerais. Belo Horizonte: Autêntica, 2005

ROSA, João Guimarães. Ave, palavra. 6 ${ }^{a}$ ed., Rio de Janeiro: Nova Fronteira,2009. [texto originalmente publicado na revista "O Cruzeiro", em 25.8.1957].

ROSA, João Guimarães. Grande sertão: veredas. $22^{\mathrm{a}}$ ed., São Paulo:Companhia das Letras, 2019.

SANTIAGO, Silviano. Genealogia da ferocidade: ensaio sobre Grande sertão:veredas, de Guimarães Rosa. Recife: Cepe, 2017.

Vasconcelos, S. G. T. (2002). Homens provisórios. Corenelismo e jagunçagem em Grande sertão:veredas. Scripta, 6(10), 321-333. Recuperado de

http://periodicos.pucminas.br/index.php/scripta/article/view/12410.

WOOLF, Virginia. Orlando. São Paulo, 1982. 